\title{
Cultivating a Professional Culture of Peace and Inclusion: Conceptualizing Practical Applications of Peace Leadership in Schools
}

\author{
Whitney McIntyre Miller* and Annmary S. Abdou \\ Attallah College of Educational Studies, Chapman University, Orange, CA, United States
}

Beyond the role of educating students across all academic domains, school leaders are tasked with the monumental responsibility of creating positive, engaged systems and cultures that embrace the growing cultural, economic, linguistic, and cognitive diversity in the United States landscape. With collective goals to create peaceful learning environments with capacity to serve diverse learners, many school leaders have embraced school-wide prevention and intervention efforts, such as Multi-Tiered Systems of Support (MTSS) for social-emotional and behavioral development of students. Unfortunately, due to the inherent complexities and fragmentation of such efforts, many school leaders have continued to experience significant barriers to sustainable systems

OPEN ACCESS

Edited by: Lauri Johnson, Boston College, United States

Reviewed by:

Marsha E. Modeste, Pennsylvania State University, United States Kerry Robinson, University of North Carolina at Wilmington, United States

*Correspondence: Whitney McIntyre Miller wmcintyr@chapman.edu

Specialty section:

This article was submitted to Leadership in Education, a section of the journal Frontiers in Education

Received: 28 March 2018 Accepted: 21 June 2018 Published: 16 July 2018

Citation:

McIntyre Miller W and Abdou AS (2018) Cultivating a Professional Culture of Peace and Inclusion: Conceptualizing Practical Applications of Peace Leadership in Schools. Front. Educ. 3:56 doi: 10.3389/feduc.2018.00056 change. Throughout the following discussion, the authors argue that the school-wide programs most commonly utilized in schools lack the explicit organizational structures for integrating culturally responsive practice, leadership development, and collaborative community building processes that are essential to sustainable implementation. Therefore, this conceptual paper aims to explore the possibilities for practical applications of the Integral Perspective of Peace Leadership (IPPL, McIntyre Miller and Green, 2015) within school systems change efforts by shifting focus from direct student skill development toward a more integrated and systems-oriented approach aimed at strengthening culture and capacity within communities of educational leaders. The IPPL can "connect the dots" and provide a strong foundation through which school-wide change is possible and more sustainable. By challenging individuals, schools, communities, and organizations to examine and include Innerwork; theories, behaviors and practices, or Knowledge building; Communities of practice; and Environment work, such as systems and global thinking (Mclntyre Miller and Green, 2015), the implementation of the IPPL may "challenge issues of violence and aggression and build positive, inclusive social systems and structures" (Mclntyre Miller, 2016, p. 223). The purpose of this paper is twofold. First, there is a discussion of how the elements of the IPPL connect to school culture and system change. Second, specific examples, such as character development, mindfulness, school-wide positive behavior supports, social-emotional learning, professional learning communities, home-school connection, systems thinking, and distributed leadership, will demonstrate how school leaders might engage, using consultants and an implementation team, in the work to create positive, equitable school cultures.

Keywords: school climate, school culture, peace leadership, systems thinking, professional development 


\section{INTRODUCTION}

There has been an ongoing challenge in the United States, and elsewhere, to create thriving and culturally inclusive environments and organizations. This has been even more aggressively tested in recent shifts in our socio-political landscape. Schools, as nested microcosms of the larger societal context, tend to experience parallel challenges in creating organizational cultures that acknowledge and celebrate the diversity present in their student and community populations. Despite the growing cultural, economic, and linguistic diversity in U.S. school systems, there is an overwhelming need for more leadership guidance on how to integrate culturally responsive practices within schools (Minkos et al., 2017) while effectively implementing systems change programs.

As Multi-Tiered Systems of Support (MTSS) for academic, behavioral, and social supports have gained traction in both research and educational legislation (California Department of Education, 2017), more schools are adopting school-wide prevention and intervention programs to meet the needs of all learners. In addition to unique personality traits, student populations are usually made up of a variety, and intersectionality, of characteristics including, but not limited to racial, cultural, religious, linguistic, cognitive (i.e., ability levels, learning styles, strengths), and gender diversity. Considering the growing diversity within schools, and the fact that many historically marginalized groups of people continue to fall behind in school achievement and outcomes (Williams, 2011), school research and policy have continued to shift toward more systems level support frameworks. Through the adoption of high quality MTSS, schools are better equipped to meet the diverse needs of all students using adaptable support systems that can be adjusted based on individual and larger group needs.

While multi-tiered prevention and intervention supports have historically been emphasized for academic systems, the undeniable links between social-emotional health and both academic and social success (Thapa et al., 2013) have catalyzed many school district leaders to seek out school-wide programs to better support mental and behavioral health of students. Mental health support systems have generally been identified as an area of weakness within our school systems, particularly for students of color and low socioeconomic status (Kataoka et al., 2002). By incorporating MTSS and programs that address positive behavior and social-emotional skills, school leaders have a unique opportunity to nourish multiple aspects of child development. Despite challenges that accompany such efforts, school-wide movements to address systematically student social-emotional well-being in schools are exciting and a promising step toward increasing equitable access to education.

While the increase in collective energy and enthusiasm toward high quality MTSS programming and positive systems change is an important piece of the puzzle, systems change in any organization is complex and requires many considerations. As school leaders grapple with the lasting consequences of rigid educational practices that have been shaped by the external pressures of "high-stakes" policies (Cavendish et al., 2016), the evolution into flexible and multi-tiered support systems have been even more difficult. With the promise of improved student outcomes and implied consequences of positive school cultures and climates, many school district leaders have enthusiastically inundated their school sites with school-wide programming efforts (often multiple and simultaneously). Unfortunately, these well-intentioned administrative decisions often result in resistance and burnout among the very stakeholders they are meant to empower (Mendenhall et al., 2013).

While most systems-level prevention programs and national educational leadership standards also include general goals of promoting equity and social justice in schools, they typically do not include explicit or cohesive leadership development processes to guide these implementation efforts (Minkos et al., 2017). Haphazard and disjointed implementation efforts have also resulted in overwhelmed educators, limited teacher buyin, and high leadership turnover (Adelman and Taylor, 2007; Turri et al., 2016). Further, school-wide program implementation efforts often lack critical system variable considerations, such as intentional and clear processes to integrate culturally responsive practice, continuous leadership development and support, and ongoing collaborative community building opportunities (Kincaid et al., 2007; Banks and Obiakor, 2015). While it would be inaccurate to suggest that all school-wide programs to improve student and environmental outcomes have been completely unsuccessful, there has been a historical trend of valuable school-wide interventions failing to sustain and/or be replicated (Adelman and Taylor, 2007). In efforts to continue building on the positive progress that many school leaders and researchers have made in the adoption of systemsoriented perspectives and interventions, this paper aims to explore the potential application of the Integral Perspective of Peace Leadership (IPPL, McIntyre Miller and Green, 2015) to improving school-wide implementation efforts in schools. By reframing leadership development processes through the IPPL, we argue that sustainable and culturally sensitive systems change goals may be more attainable.

The application of the IPPL to the school context is unique as it moves beyond specific student outcome improvements and even the traditional, yet diverse, concepts of school climate. For increased clarity throughout this discussion, we define and contrast the concepts of school climate and school culture here. School climate is a complex construct that is "composed of the affective and cognitive perceptions regarding social interactions, relationships, safety, values, and beliefs held by students, teachers, administrators, and staff within a school" (Rudasill et al., 2018, p. 12). There is not one universally agreed upon set of school climate variables nor is there one universal way to measure school climate in any given school. School culture, on the other hand, is conceptualized as the actual practices, artifacts, and cultural values that may be a result of deliberate group learning process and usually influenced by organizational leadership (Lindahl, 2011). School culture is less understood and explicitly studied within the school-based literature and is often used interchangeably with school climate. While these two concepts are undoubtedly related, they are distinct elements of the school environment. In essence, the intentional development of peaceful and inclusive school cultural practices may be a prerequisite to 
improving the overarching school climate, which more accurately defined as how those cultural qualities are actually perceived by all school community members.

Within the current article, the concept of school culture is more salient to the processes discussed, as the IPPL elements are rooted in cultural change (e.g., perspectives, beliefs, values, practices, etc.) for school leaders, communities, and systems from within. While school climate assessments may be used throughout the implementation and monitoring of the IPPL, this is not the focus of the current discussion. There are several high quality school climate measures that are available for use before and during the IPPL implementation process, which can enhance decision making throughout (Zullig et al., 2010; Marx and Byrnes, 2012; You et al., 2014; Bear et al., 2015). We argue that the IPPL may serve as a theoretical systems change agent that "connects the dots" through improving cohesion and collaborative processes within a professional culture. This collective culture and synergy may then be viewed as the primary objective of the IPPL, which we argue would result in the increased potential for effective and sustainable systems change efforts, such as those that fall within the overarching scope of MTSS.

Through our analyses of the IPPL components and relevant school structures, we posit that this framework can be applied to cultural and systems change efforts in several ways. First, by providing concrete catalysts for cultural change among school leaders through cohesive and innovative professional development processes. Second, by increasing meaningful and clear connections between staff culture, professional development, and actual school practices. Finally, by focusing on the social justice components of the IPPL to embed culturally responsive and equitable school practices throughout every aspect of professional development and practical implementation efforts. While the concepts of the IPPL can be applied throughout both academic and social-emotional support structures in schools, this article will highlight examples of school-wide socialemotional and behavioral systems that are typically intended to be implemented within MTSS frameworks. Although it is beyond the scope of this paper to delve into the specifics of how these school-wide prevention and intervention models should be implemented throughout the multiple tiers, we posit that stronger and more cohesive professional development with the IPPL guidance has the potential to improve implementation of these complex systems. More so, the current discussion of the IPPL is centered on the development and empowerment of school leaders who are tasked with systems change efforts, rather than the direct intervention efforts themselves. Therefore, we argue that systems change efforts, such as MTSS, may be strengthened through improved professional skills and culture. By reframing school systems change within the IPPL, we propose a holistic approach with implications for theory, professional development, implementation science, and social justice efforts.

\section{PEACE LEADERSHIP}

Peace leadership is defined as "the intersection of individual and collective capacity to challenge issues of violence and aggression and build positive, inclusive social systems and structures" (McIntyre Miller, 2016, p. 223). A space where personal work toward peace meets collective efforts at local and systemic change. Peace leadership, a growing subfield in leadership studies, looks to build peace, both positive-that which focuses on new efforts at peace and system change, and negative-that which focuses on challenging violence and aggression (Galtung, 1996), into our groups, communities, schools, organizations, and societies. While there are several emergent perspectives on peace leadership (Dinan, 2012, 2018; Ledbetter, 2016; Schellhammer, 2016, 2018; Amadalas, 2018; Chinn and Falk-Rafael, 2018), this article focuses on McIntyre Miller and Green's (2015) Integral Perspective of Peace Leadership (IPPL) for understanding peace leadership and its applicability to the life, culture, and systems of schools.

The IPPL is a theoretical framework based on Ken Wilber's (2000) All Lines, All Quadrants (AQAL) model of integral theory. Designed as a quadrant model, with the notion of each quadrant working together to form a whole, the model aims to define the four areas of functioning to reach goals that further our capacity as humans (Wilber, 2000). These areas include: (1) the I quadrant, which focuses on individual, interior experiences as defined within the self; (2) the WE quadrant, which focuses on collective, interior experiences, such as group work; (3) the IT quadrant, which focuses on individual, exterior experiences, such as knowledge acquisition; and (4) the ITS quadrant, which focuses on the collective, exterior experiences, such as the networks and systems that surround us (Pacific Integral, 2003; McIntyre Miller and Green, 2015). McIntyre Miller and Green (2015) initially plotted elements of peace and leadership seen in the literature into the AQAL model to create the IPPL. Additional literature, as discussed by McIntyre Miller (2016), is also shared herein to further elucidate the quadrants. The quadrant labels have been adapted from Wilber's (2000) initial terms by McIntyre Miller (2017) in the Peace Leadership Development Curriculumthese updated labels will be used for the remainder of this paper.

The I quadrant, that of Innerwork or the readiness to engage in peace work, involves internal traits and practices such as authentic leadership, nonviolence, pacifism, empathy, optimism, flexibility, adaptability, and vision (Boyer, 1986; Reychler and Stellamans, 2005; Sarsar, 2008; Lieberfeld, 2009, 2011; Chappell, 2013; Matesi, 2013). The WE quadrant, that of Communities working together to build relationships and capital, involves building group practices (Spreitzer, 2007) and organizational capacity (McIntyre Miller and Wunduh, 2015), using democratic processes (Harber and Davies, 2003), adaptive work (Goulah and Urbain, 2013), and creating relationships and creative strategizing (Ganz, 2010). The IT quadrant, that of Knowledge, or the theories, behaviors and practices of peace leadership, involves the use of morals in practices (Ledbetter, 2012, 2016); servant leadership (Ngunjiri, 2010); and skills such as communicationparticularly dialogue, negotiation, and creating appropriate structures (Reychler and Stellamans, 2005). The ITS quadrant, that of the larger Environment working toward structural and systemic change, involves understanding of larger nonviolent social movements (Chappell, 2013), filling the leadership gap in 
such movements (Ganz, 2010), inclusion of diverse populations in this practice (Adler, 1998), and creating a culture of peace (Schellhammer, 2016). Figure 1 below demonstrates some of the important elements in each quadrant as demonstrated in the peace leadership literature, and broader themes from peace and leadership studies.

As with Wilber's (2000) AQAL model, the IPPL (McIntyre Miller and Green, 2015) is designed for the quadrants to be interwoven-each are a nestled part of the whole, and all must be present for peace leadership to occur. It is also important to note that the quadrants, although they appear static, are not. Figure 2 provides a visual for how the quadrants may, in actuality, overlap. Many practices and skills blur the lines between the quadrantsthey are plotted in quadrants here for ease of discussion. The capacity of each quadrant needs not be full, but work in each quadrant, in some capacity, is essential. In many ways, the IPPL, in addition to including system thinking, is operating in a systems perspective by focusing on layered systems and wholes, thus reflected systems within systems (Bronfenbrenner, 1992; Capra and Luisi, 2014).

\section{Peace Leadership in Schools}

Given the clear potential for peace leadership as a catalyst for positive and sustaining organizational and cultural change, it is a worthwhile endeavor to explore the possibilities of utilizing peace leadership concepts within the context of schools. Schools are uniquely positioned organizational entities in our society that impact and shape the development of most young children into their adult lives. Given the enduring achievement and discipline gaps for students of color, and those living in poverty (Gregory et al., 2010; Skiba et al., 2011; Williams, 2011), along with the generally lower quality school experiences for these students (Watkins and Aber, 2009; Dessel, 2010; Espinoza and Juvonen, 2011; Fan et al., 2011), the IPPL provides a systems change framework that considers student and staff diversity with goals of achieving greater equity in schools and student outcomes. The success and quality of our school systems for all students have significant relevance to our broader society, both in citizen productivity and prosocial behavior. Therefore, it is imperative that school leaders adopt systems-oriented perspectives where success is measured within and beyond

\begin{tabular}{|c|c|}
\hline $\begin{array}{c}\text { Innerwork } \\
\text { Empathy, Forgiveness, Compassion, } \\
\text { Reflection, Mediation, and Authenticity }\end{array}$ & $\begin{array}{c}\text { Knowledge } \\
\text { Conflict Resolution, Communication, } \\
\text { Mediation, Restorative Practices, } \\
\text { Reconciliation, and Negotiation }\end{array}$ \\
\hline $\begin{array}{c}\text { Adaptive and Servant Leadership, Building } \\
\text { Relationships and Capital, Coalition Building, } \\
\text { and Democratic Processes }\end{array}$ & $\begin{array}{r}\text { Comstems Thinking, Nonviolent Social } \\
\text { Movements, Culture of Peace, Distributed } \\
\text { Leadership and Advocacy }\end{array}$ \\
\hline
\end{tabular}

FIGURE 1 | Elements of the Integral Perspective of Peace Leadership.

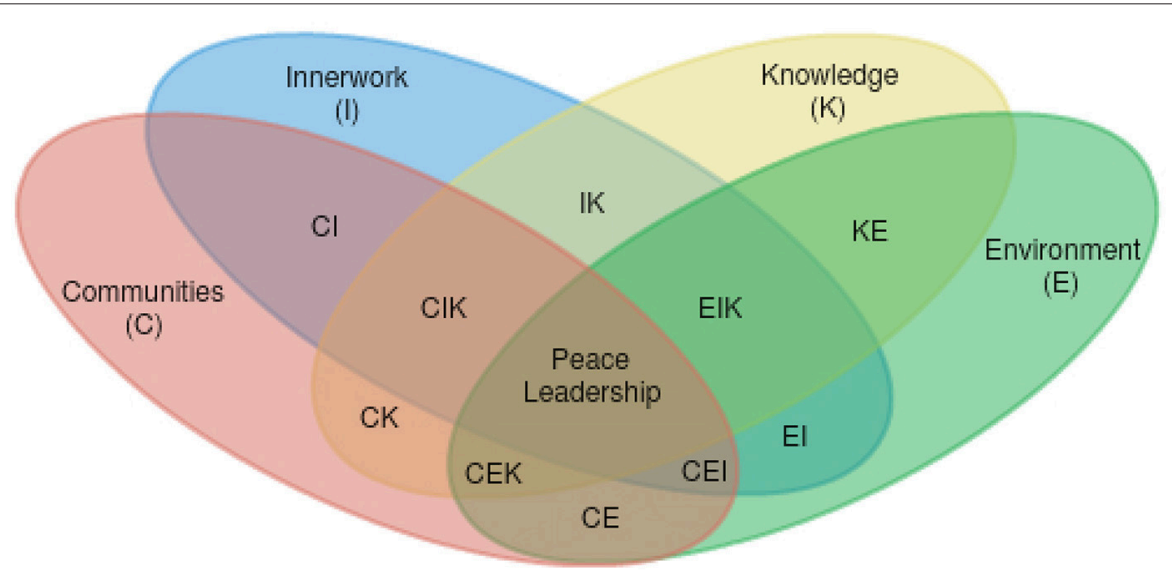

[online diagramming \& design] Creately.com

FIGURE 2 | The inter-woven elements of the Integral Perspective of Peace Leadership. 
the immediate environment. In the IPPL, school leaders are perceived as the vehicles for this type of reverberating change.

Schools consist of leadership hierarchies that range from student leadership, which is outside the scope of this paper, to district and state leadership, with teachers being the largest category of school leaders who may have the strongest potential for collective influence (Rutherford, 2006). While power distribution among school leaders resemble most organizations in terms of authority and policy creation (i.e., top down), the school leaders with the most influence on student outcomes may arguably stem from those lower on the leadership hierarchy, which is why it is essential to include all educators as leaders of cultural and systems change process (Williams, 2013). For example, while district leaders may define broad policy and general practices, it is usually the principal and internal school administrators who use their skills and values to foster the procedural and cultural norms of their given schools, which impact teacher practices. From there, school psychologists and school counselors can be viewed as the mental health leaders of their schools and influence the way that school support systems can be effectively utilized across the spectrum of diverse learning and/or mental health needs throughout various school environments (Curtis and Stollar, 2002). Teachers, who may not always consider themselves as leaders within the context of the leadership hierarchy, are tasked with leading groups of students and families through their ongoing educational journey and usually have the most direct impact on their students' development. Even support staff members who may not have any tangible "power" (i.e., office supports, instructional aides, cafeteria staff, custodial staff) may still be considered leaders, as they are adults who model and embody peaceful behavior and interactions for the youth they serve.

Therefore, when leadership in schools is viewed as a distributed and shared responsibility (while still maintaining accountable and connected leadership linkages throughout every level), the potential for successful systems change may be higher than traditional top-down approaches (Adelman and Taylor, 2007). It is important to note that while most adults in a school setting can be considered a leader in cultural change efforts, this does not mean that intentional leadership processes and structures are irrelevant. In fact, a key element to using the IPPL in schools is to make the unique roles and responsibilities of each school leader transparent and to provide the appropriate training and support to make these possible. This investment in school leadership development, and the resulting culture, is not only beneficial to the children and families served then, but crucial to our collective journey toward a socially just and peaceful world.

In the following pages, we will explore the role of the IPPL by examining existing school programs and envisioning them within this interconnected framework to shift school cultures in the direction toward peace and inclusion. Given the fact that there are so many evidence-based school wide socialemotional and behavioral programs available from which schools can choose (What Works Clearinghouse, 2018), we argue that the actual programs chosen by a school are less consequential than the strength of an implementation approach that is rooted in systems perspectives and leadership development systems.
Building from the IPPL quadrant elements, we reflect on increasingly common school-based practices that fit within (and across) these quadrants and how they may be strengthened with this approach. While practices discussed are not an exhaustive list of school practices that might be applied, they should be viewed as common examples used to illustrate potential application of the IPPL in schools. As such, is it important to conceptualize the IPPL as a flexible framework that may be individualized to a particular school's practices, community, and needs. As seen in Figure 3, our examples include character development and mindfulness in Innerwork, social-emotional learning and restorative practices in Knowledge, professional learning communities, and home-school connection in Communities, and distributed leadership and systems thinking in Environment.

\section{PREPARATION CONSIDERATIONS FOR PEACE LEADERSHIP IN SCHOOLS}

Prior to discussing each element of the IPPL, in this section of the paper, we consider the steps a school may take for overall peace leadership implementation toward cultural and systemic change. First, we propose the use of a consultancy-based approach to help school leaders think through implementation. Second, we encourage implementation through a professional development approach. Finally, we recommend the creation of a Peace Leadership Advisory Group to ensure mutual participation and shared leadership. Each of these suggestions will be discussed in detail below.

\section{Organizational Consultation Approach}

As would be the case for any systems and cultural change effort in schools, we recommend an organizational consultation approach for the integration of the IPPL into cultural and systems change efforts. Throughout the following sections, we frame discussion and examples from a consultative vantage point to enhance this theoretical discussion. In this case, an identified consultant or group of consultants (e.g., school psychologists, school counselors, university researchers, administrators, etc.) facilitates internal efforts to establish the foundational structures needed for successful implementation (Meyers et al., 2012). School-based organizational consultants typically have a strong understanding of systemic influences within school contexts and are important resources for cultural and systems change efforts.

Consultants working toward peace leadership development should have some expertise in existing theory, and a commitment to the ongoing internal and external work needed (which, fortunately, is inherent to many school-based consultants). Prior to engaging in the IPPL activities, consultants and internal key leaders (i.e., administration) should invest time in conducting a variety of needs assessment activities (e.g., surveys, focus groups) to gauge perceptions, readiness for change, and as a way to include school leaders in the initiation and development of the IPPL implementation trajectory. The active and intentional involvement of all teachers and staff members in this process has been identified as a key indicator of successful systems change 


\begin{tabular}{|c|c|}
\hline$\stackrel{\text { Innerwork }}{\text { Character Development, Mindfulness }}$ & $\begin{array}{l}\stackrel{\text { Knowledge }}{\text { Positive Behavior Interventions, Social- }} \\
\text { Emotional Learning }\end{array}$ \\
\hline $\begin{array}{l}\qquad \frac{\text { Communities }}{\text { Professional Learning Communities, Home- }} \\
\text { School Connection }\end{array}$ & Systems Thinking, Distributed Leadership \\
\hline
\end{tabular}

FIGURE 3 | Elements of the Integral Perspective of Peace Leadership in Schools.

and related professional development endeavors (Meyers et al., 2012; Mendenhall et al., 2013; Bayar, 2014).

\section{Professional Development Considerations}

Viewed as a holistic approach to professional development throughout the school ecosystem, the IPPL may be seen as the glue that binds existing school programming (given that these are evidence based and congruent with the school goals) and potential new skills and practices together. For example, in a school with multiple programs within their MTSS efforts, it would be important to evaluate all activities and resources used in various efforts and determine effectiveness, gaps, and overlapping systems. In other words, we conceptualize the IPPL as a systemic approach to strengthening school professional development processes in ways that enhance personal capacities and professional cultures through cohesion and efficiency. Furthermore, Overstreet (2017) suggests that professional learning opportunities must account for the complexities in both teacher and student cultural characteristics and that these factors cannot be treated as separate entities. Therefore, professional learning processes may then become the vehicles to improve cultural responsiveness for the needs of the school leaders as well as the needs of the students and families served. The integration of professional development systems with intentional cultivation of positive and inclusive professional cultures is at the core of what the IPPL can contribute to systems change efforts.

\section{Peace Leadership Advisory Group (PLAG)}

While detailed specifics regarding implementation planning for the IPPL within a school system is beyond the scope of this paper, and would be individualized to the unique needs of a particular school community, for the purpose of illustration, some general key actions will be discussed here. A primary step toward initiating sustainable systems change is selecting participants for a core implementation team (Jenlink et al., 1998); which, in this case, we refer to as a peace leadership advisory group (PLAG). The PLAG can consist of teachers, parents, counselors, psychologists, administrators, and/or other staff members who are committed to encouraging their peers to engage in the work of incorporating peace leadership skills and practices throughout the school environment. While there is a great deal available on forming such teams, Chinn and Falk-Rafael's (2018) PEACE and power principles of group formation may serve as a guide to those building these groups.

Regardless of set up, ideally, a PLAG would work as a collaborative and integrated process to any other implementation teams working within a school or district. In school districts where there are multiple and disconnected systems change efforts occurring simultaneously, it may even be helpful to consider collapsing teams into one larger PLAG who can work together to make connections between existing programs and embed the IPPL throughout. Like every part of the implementation process, the development of the PLAG should be a collaborative approach with input from all. PLAG members should be given the appropriate time and resources to carry out their responsibilities (e.g., stipends, extra planning period, relief other job duties, etc.). For a conceptual overview of the implementation of the IPPL for positive cultural and system change through the use of organizational consultant(s) and a PLAG, please see Figure 4. Once established, the first task of the PLAG, and those throughout the school, may be to invest in Innerwork activities.

\section{INVESTING IN INNERWORK}

The Innerwork quadrant is the space where teachers and administrators can begin to prepare themselves for the foundational perspectives related to peace and leadership. In this quadrant, work is done to bring a deeper understanding of ourselves, and in so doing, provide the opportunity to better understand others-especially those who may seem quite different from ourselves. This critical awareness of the cultural, linguistic, and ability diversity of students, as well as the self-awareness of one's own culture, biases, and power positions is a pivotal component to culturally responsive and inclusive practices (Mena and Rogers, 2017; Minkos et al., 2017). While intentional work to increase the cultural selfawareness of educators is not a common practice in professional development processes within schools, this innerwork is a central component to the IPPL. Considering the plethora of research surrounding cultural mismatch between students and educators, as well as the potential consequences of this phenomenon for certain populations (i.e., "hidden curriculum," Vélez and Saenz, 2001; Fenning and Rose, 2007), opportunities for cultural self and environmental reflection should begin within innerwork activities, and be embedded throughout all of the IPPL quadrants. 


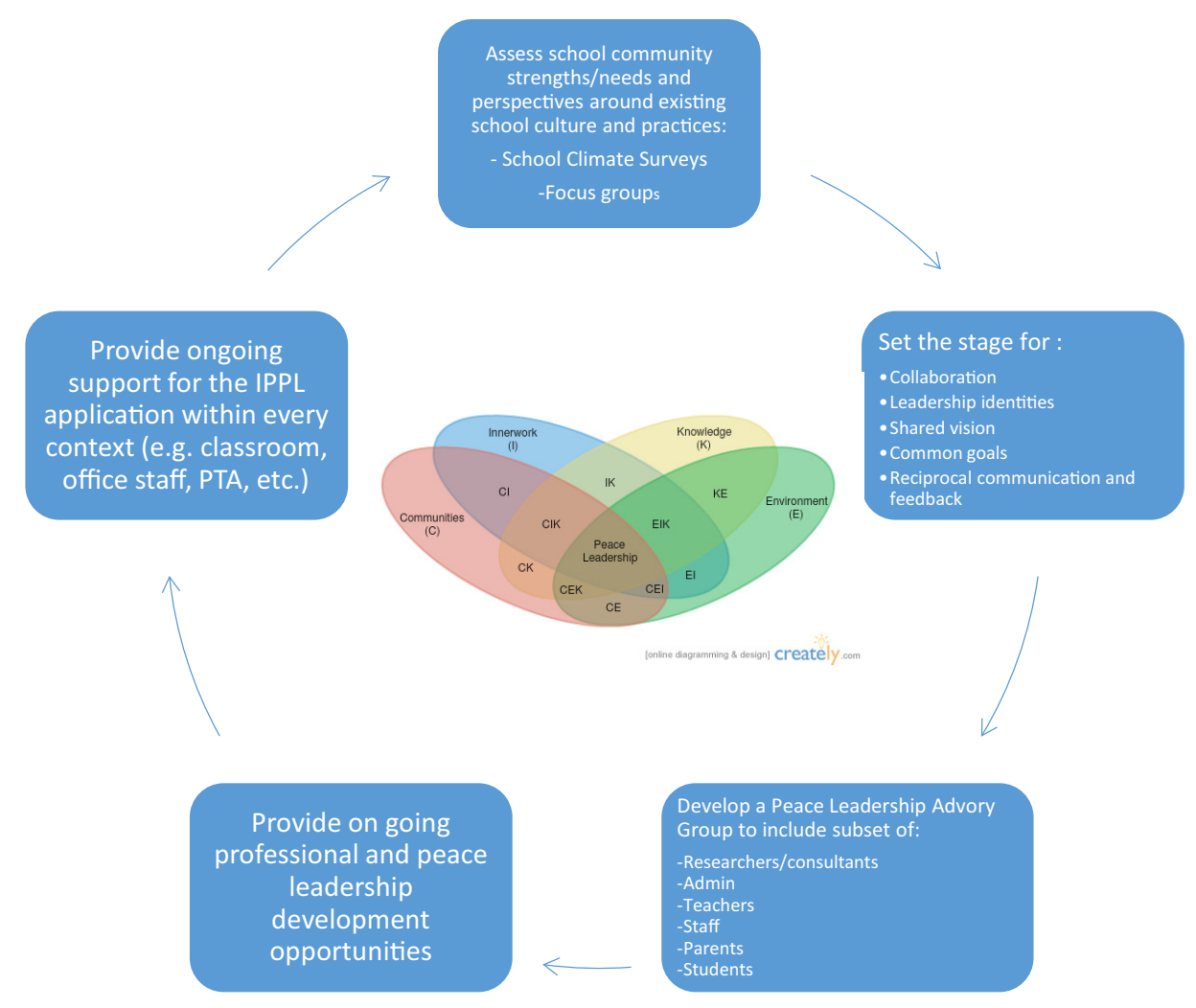

FIGURE 4 | The Integral Perspective of Peace Leadership school implementation cycle.

The Innerwork quadrant is a space for self-reflection and selfexamination, which requires focus and continual efforts to stay internally engaged in the work, taking advantage of the rare opportunity to put ourselves first in our change efforts-as this work is as essential to the process as any of the other quadrants.

Ironically, opportunities for this type of internal work is often available for students, but is not necessarily personally embraced by the teachers, staff, and administrators, despite the fact that these skills would likely also be beneficial to nurturing relationships between adults and children. To assume that innerwork is a merely a personal preference or choice, and not relevant to the job of a school leader, is unwise and inaccurate. While many teachers and administrators adopt a narrow conceptualization of their role within the school system (e.g., specific subject, curriculum discipline, etc.), it is important to remember that many students require certain environmental and relational conditions for learning to occur and be enhanced. Conditions for student engagement in the learning process may include safety within the educational environment, perceptions of caring relationships, opportunities for meaningful participation, and general school connectedness (Hyman et al., 2003; Jennings, 2003). School leaders, particularly teachers, are best positioned to cultivate these interpersonal and environmental conditions through intentional planning and modeling/guidance of peaceful behaviors. Furthermore, given the significant influence that adults have on the students they support in the school setting, innerwork must also move beyond focusing on the individual leader to also being systematically integrated within school norms and curriculum.

Practicing innerwork at all levels of the school system can potentially create an active and healthy community across the spectrum of the school. The collective engagement in innerwork activities among school leaders may also create meaningful opportunities for collaborative reflection and collegial support among school leaders with these mutual goals. Some of the important ways schools may increase their innerwork capacities include, but are not limited to: understanding their own and others' worldview, practicing empathy, placing value on human dignity, mindfulness, meditation, embracing forgiveness, listening, love, engaging in authenticity, tolerance of ambiguity, and stress and anger management (McIntyre Miller, 2017). Two of the ways these practices of innerwork are already embedded in schools is through character development and school-based mindfulness interventions. While these areas certainly pertain to the Knowledge quadrant as well, they are discussed more in depth within the Innerwork quadrant as they relate back to the internal work that educators must engage in along with their students for effective integration into the overarching school culture. The next two sections discuss these areas in particular.

\section{Character Development}

The concept of cultivating positive character and moral qualities as part of an educational experience is not new to schools. In 
fact, there has been enough collective agreement within our society on the importance of the innerwork skills that "character education" programs for student development have been on the rise for the past several decades. There are even multiple national organizations committed to expanding character development programs in schools (e.g., the Character Education Partnership, the Character Counts Coalition, and the Communitarian Network; Lickona, 1997). Lickona (1997) argues that proactive efforts to teach "good character" should be central in all schooling as these traits are beneficial for the individual life experience as well as collective humanity. In other words, good character is an essential component to both personal and collective peace, harmony, and productivity. Character development in the school context is broadly defined as purposeful attempts to foster positive student character traits such as intrapersonal values (e.g., honesty, courage, responsibility), interpersonal values (e.g., caring, respect, empathy, fairness, tolerance of diversity), and civic virtues (e.g., citizenship, patriotism, justice: What Works Clearinghouse, 2018).

Successful character education programs do not necessarily need to be purchased but can be developed and implemented universally by school communities to meet their unique needs and match their community value systems (Colorado State Department of Education, 2000). Consistent with the IPPL, which includes working individually and collectively to foster nonviolent and positive communities and societies, character education initiatives are rooted in the goal of developing future generations of leaders and society members who will uphold and contribute to these values. While the concept of character education is a hopeful one, the potential for its effectiveness is largely dependent the quality of the professional development that supports implementation. In addition, we argue that professional development should include opportunities for innerwork to ensure that school leaders charged with teaching these skills are also embracing and modeling the values and behaviors they expect of their students. As with many of the practices discussed in this article, character education is as strong as the professional culture within which is planted and nurtured.

\section{Mindfulness}

Another emerging school practice that is consistent with the innerwork concepts of the IPPL is the integration of mindfulness as both a school, or class-wide, practice, as well as a more individualized intervention. Mindfulness began its emergence into American cultural practices through patient care in 1979, when mindfulness-based stress reduction (MBSR) made its debut at the University of Massachusetts Medical Center's Stress Reduction Clinic (Williams and Kabat-Zinn, 2011). Since then, the use of mindfulness techniques for medical and psychological interventions has become a worldwide phenomenon. Given the consistent research findings across three separate meta-analyses that indicate the widespread effectiveness of mindfulness-based interventions (Baer, 2003; Grossman et al., 2004; Hofmann et al., 2010) and the evidence of successful adaptation to interventions for children (Burke, 2010), it is no surprise that school-based researchers are strongly advocating for an increase in the application of mindfulness interventions within school settings (Felver et al., 2013). School-based mindfulness interventions have been effectively implemented throughout multiple tiers of school-wide service delivery including universal interventions (i.e., integrated with social-emotional learning curricula and school-wide prevention models), targeted group interventions (i.e., small groups of at-risk students with psychosocial, educational, or behavioral difficulties), and intensive interventions (i.e., individual supports for high-need students that may have identified disabilities) (Felver et al., 2013). Based on the demonstrated effectiveness of school-based mindfulness interventions, it is clear that this area of innerwork can be a powerful practice for both students and school leaders alike, and should therefore be utilized in schools to a far greater extent than it currently is. While school-based mindfulness interventions have yet to be considered a widespread practice, we argue that the integration of mindfulness within professional development may contribute to the continued growth of these valuable practices.

\section{Innerwork Discussion}

Both of these innerwork examples should be conceptualized within an MTSS framework, where all students receive some exposure and practice with the skills (i.e., universal), with opportunities for more intensive and individualized interventions for students who need more. With both character education and mindfulness, the application of school-based practices are focused primarily on students, rather than on all members of the school community. There does not seem to be the same professional value or expectation for adult leaders to do this work themselves, or to adhere to the same principles in various situations.

For example, while respect and empathy are common traits that are included in character education programs, some teachers and administrators continue the utilization of punitive discipline strategies with students (e.g., exclusion, yelling), which many students experience as humiliating, disrespectful and damaging to their relationships with adults in school (Mitchell and Bradshaw, 2013). The negative impact of punitive discipline practices is especially prevalent for males, students of color, and students with disabilities (Smith, 2015), which provides more evidence that punishment and exclusionary techniques are not only ineffective but also discriminatory to certain groups. Students who experience these types of interactions may come to believe that the disciplinarian does not have empathy to circumstances that may have contributed to the misbehavior in the first place (e.g., family/peer conflict, finding the work too difficult, trauma, etc.). These dynamics can result in mistrust toward teachers and administrators, missed instructional time, as well as continued problem behaviors (Arcia, 2006; Mitchell and Bradshaw, 2013). Furthermore, from a developmental perspective, children have less capacity than adults do to engage in self-regulation and peaceful problem-solving (Twemlow et al., 2005) so without appropriate adult modeling of these skills, it becomes even less likely that children will learn these skills. In the same way, that supports can be intensified based on student need, school leaders who need more training or individual consultation 
for the various personal and professional skills should have access to these supports as well.

\section{Innerwork for Professional Development}

It is, therefore, a reasonable expectation that school leaders use empathy, compassion, mindfulness, peaceful conflict resolution, and patience to model the very qualities they would like to see in their students, regardless of the circumstances. In order to bridge the gap between the qualities that school leaders value for their students, and what they embody themselves, it is important to confront the need for more innerwork among all members of the school community, and not just for the students. For attempts at character and prosocial behavior development to be successful, the values must be owned by and permeate all levels of leadership. One simple way to begin this process is to incorporate elements of innerwork into professional development processes as an expected and respected component. This would require a commitment to the integration and practice of innerwork for all school leaders and could be encouraged through the PLAG. Approaching the skills and practices inherent to the innerwork quadrant from a growth mindset perspective (Dweck, 2006) may help school leaders embrace their own abilities to continue growing and learning in personal areas of weakness. By strengthening the incorporation of character education and mindfulness practice in the universal support structures of MTSS, school leaders may increase their opportunities for practice and guidance for their students as well.

\section{Role of the PLAG}

The creation of meaningful opportunities for innerwork among teachers, staff, and administrators is an important precursor to the actualization of peace leadership within school environments. PLAG members should take some time to determine what areas of innerwork are most important and relevant to their unique school community, and make plans about how to incorporate meaningfully opportunities for growth throughout professional development processes and other support systems. For example, the PLAG may decide to focus on mindfulness and stress/anger management based on the current identified needs among their community of leaders. The PLAG may decide to include opportunities for professional learning, practice, and discussion around these skills at staff meetings throughout the year, and include regular communication and encouragement through various forms of personal interaction as well as communication through media. In addition, school counselors or school psychologists may offer group and/or individualized consultation services to support teachers and staff in their utilization and teaching of these skills and practices into their everyday service to children.

For schools that have existing character education programs, the PLAG may choose to take a more integrated approach and simultaneously focus on the same character traits their students are practicing for staff development purposes. It is not uncommon that schools adopt character education programs, but actual implementation is often limited to a shallow introduction of the concepts (e.g., signs around campus, notices in bulletins) without depth or opportunities for practice. By building on an existing structure like a character education initiative or schoolbased mindfulness practices, the PLAG may be able to develop an innerwork action plan that strengthens these efforts while creating conditions within which school leaders may reflect on their own expression of the very same qualities. This process may include developing or negotiating a collective understanding of the character traits of focus, training on effective methods for teaching and cultivating traits, and self-exploration about how school leaders are personally modeling and/or embodying the traits discussed. Regardless of how the PLAG ultimately decides on how to approach the Innerwork quadrant within their unique school communities, it is critical that there is careful consideration of how to develop a set of group norms and expectations so that this work can be done in a safe and supportive environment. One way to do this is to build upon the knowledge in the school, and from the literature.

\section{KEEPING UP IN KNOWLEDGE}

The Knowledge quadrant provides the space for understanding, processing, and practicing the theories, behaviors, and skills that inform peace leadership. This section incorporates scientific and practical information that informs our work in the other quadrants and in practicing peace leadership in general. The Knowledge quadrant of the IPPL is perhaps the one that is most familiar to school communities. In socialemotional and behavioral support structures in schools, this work often takes the form of the trainings, skill-building, and professional learning that increase school leader knowledge around evidence-based practices to reduce violent behaviors and increase pro-social behaviors. Knowledge can be gleaned from academic programming, professional development contexts, and self-learning, among other ways. In broad organizational contexts, this includes, but is not limited to: overarching communication practices; engaging in dialogue; understanding aggression and violence; practicing nonviolence strategies, utilizing conflict resolution, negotiation, and mediation; findings ways of reconciliation, restorative justice and peacebuilding practices, and establishing ways of creativity (McIntyre Miller, 2017).

For the purposes of this discussion, we will highlight two common and well-studied social-emotional and behavioral multi-tiered approaches in schools that are consistent with the knowledge quadrant: school-wide positive behavior supports (SWPBS) and social-emotional learning (SEL) approaches. Rooted in principles related to positive psychology and prevention, SWPBS and SEL approaches allow educators to move away from problem-focused perspectives and toward the enhancement of student strengths and pro-social attitudes and behaviors (Terjesen et al., 2004). Similar to the previous concepts discussed, SWPBS and SEL approaches are conceptualized within MTSS efforts in which intensity of supports are adjusted based on levels of need (Netzel and Eber, 2003; Sugai and Horner, 2006; Durlak et al., 2011). These school-wide models of support are consistent with the knowledge quadrant philosophies that are rooted in understanding nonviolence 
strategies, conflict resolution, and restorative justice approaches to create environments that are more peaceful. By focusing on methods that encourage the development of social-emotional skills, pro-social behaviors, and the strengthening of relationships within communities, these system level approaches have been a positive shift from the historical emphases of punishment and exclusion as methods of social control in schools. The following sections will describe the use of SWPBIS and SEL in schools and discuss how IPPL may serve to strengthen these efforts.

\section{School-Wide Positive Behavior Supports}

SWPBS are generally non-curricular behavioral support systems that are grounded in applied behavior theories (Horner and Sugai, 2015) and generally include a clear set of school-wide behavioral expectations, consistent behavior response strategies, and student behavior incentive systems; all of which are intended to alter both student and staff behaviors (Bradshaw et al., 2008). For example, schools will often have ticket or voucher systems that are consistent across the school environment, whether it be classroom, lunchroom, or playground, and students have the opportunity to earn these rewards when engaging in schoolwide set expected behaviors. While there is not any one specific program or curriculum that qualify as SWPBS, it is considered a systems change process that schools may implement to meet their unique needs by incorporating the specific set of guidelines described above. School leaders with expertise to guide SWPBS may include school psychologists, school counselors, program specialists, education specialists and administrators. There are also several organizations dedicated to the growth of SWPBS in schools (e.g., www.pbis.org, www.interventioncentral.org), which offer a number of resources for implementation across the multiple tiers.

The knowledge component of these systems change processes usually include training opportunities for the adults in schools that teach them the benefits of SWPBS, how to explicitly teach students what the desired behaviors are and what they look like, and how to positively reinforce students for engaging in these positive and pro-social behaviors. Positive reinforcement can include formal and tangible rewards that students can use as money (e.g., tokens, vouchers, points) or immediate reinforcers such as stickers and edibles. Frequent verbal praise and encouragement are also forms of reinforcement within SWPBS. Staff behaviors should theoretically shift more positively toward students as they are tasked with recognizing expected behaviors more often; and subsequently, have more positive interactions with students through the positive reinforcement system (Bradshaw et al., 2008).

While the research base underlying SWPBIS programs are sound in terms of overall "organizational health" and behavior improvement in students (Bradshaw et al., 2008; Osher et al., 2010; Vincent and Tobin, 2011), there are a few drawbacks to over-reliance on these systems. Besides some of the practical challenges of ensuring consistent and high quality implementation across all school leaders (i.e., staff buyin, consistency across settings, use of data; Kincaid et al., 2007), scholars who study effective and culturally responsive discipline practices argue that SWPBS alone may not be adequate to meet the needs of all students (Vincent and Tobin, 2011) or reduce inequities in discipline practices (Skiba et al., 2000). However, the integration of culturally responsive mechanisms within SWPBS frameworks is theorized to increase the effectiveness of this support system to reduce discriminatory discipline and improve behavior management practices (Vincent et al., 2011; Banks and Obiakor, 2015). Such culturally responsive mechanisms may include enhancing staff members' cultural knowledge and self-awareness, minimizing cultural mismatches in behavioral expectations, validating all cultures, increasing cultural relevance of academic and social contexts, establishing cultural of assessment instruments, and emphasizing cultural equity. Within the IPPL framework, these culturally sensitive enhancements to a school's SWPBS program would be deliberate and focal processes that are integrated into professional development systems. This is a clear example of how the important innerwork activities continue to inform and expand throughout the Knowledge quadrant.

\section{Social-Emotional Learning}

Another common knowledge-building effort utilized by many schools to increase peaceful and pro-social behavior is socialemotional learning (SEL) programming. Proponents of SEL programming argue that SWPBS, alone, does not adequately address the underlying social-emotional competencies that naturally lead to prosocial behaviors in children (Dodge et al., 2006). Common goals of SEL programs generally include the fostering of self-awareness, self-management, social awareness, social/relationship skills, and responsible decisionmaking/ problem solving (Collaborative for Academic, Social, and Emotional Learning CASEL, 2013). Proponents of SEL posit that social-emotional skills are equally, if not more, important than academic skills, as they are critical to the development of greater well-being and both academic and life success (Weissberg and O'Brien, 2004; Osher et al., 2010).

In contrast to the concrete behavior and reinforcement focus of SWPBS systems, the emphasis of SEL programming is in the teaching, modeling, and opportunities for practice of the social-emotional skills that underlie behavior. There are many evidence-based SEL curricula available for use and delivery by teachers (e.g., Second Step, Incredible Years, Peace Works, PATHS, Steps to Respect; CASEL, 2013) and integrated into class standard curricula. In fact, there are several student-centered SEL programs that include peace in the name and mission, and include skill-building in the areas of mediation, conflictresolution, appreciation of diversity (e.g., Peaceful Schools, Safe and Peaceful Schools, Peaceable Schools); somewhat merging the work of the Knowledge and Innerwork quadrants. In a metaanalysis of 213 school-based, universal social and emotional learning programs, which included 270,034 K-12 students, Durlak et al. (2011) found significant improvements in social and emotional skills, attitudes, behavioral and academic performance compared to controls. The connections between social-emotional skills and learning (Elias and Moceri, 2012) are important considerations in in the creation of peaceful and nonviolent school environments where learning is enhanced for all. Like any skill development process, this must include systematic and 
purposeful efforts to increase student and staff knowledge and mastery of social and emotional competencies. The embedding of SEL approaches into the expected practices of all school leaders, and ongoing opportunities for professional development, creates another anchor to the culture of peace through continuous assessment and reflection of social-emotional connection and capacity of a school community.

\section{SEL Through Restorative Justice}

Categorized within the overarching SEL for schools umbrella, Restorative Justice (RJ) is a philosophy that has gained momentum in the school discipline literature over the past few decades (Karp and Breslin, 2001) and is also a key tenet within the IPPL Knowledge quadrant. In response to the widespread use of ineffective and discriminatory zero-tolerance and punitive discipline policies, there has been an urgent call for researchers and educators to explore alternatives to exclusionary and punitive discipline practices (Teske, 2011; Skiba, 2014). With historical roots in global indigenous and religious cultural practices (Weitekamp, 1999), RJ is a paradigm that is focused in facilitating productive dialogues to increase understanding of different perspectives and movement toward reparation of harm caused by delinquent student behavior (Umbreit, 1999). Through deliberate ritual and structures (e.g., development of group norms, use of circle seating, talking pieces) participants are provided opportunities for respectful communication and group processing of crimes or offenses that have caused harm to a particular person and/or community (Karp and Breslin, 2001). Through these processes, both victims and offenders may share their personal perspectives and move toward repairing damage caused to relationships and/or community.

More recently, the concepts of RJ have been conceptualized as a formal component of a restorative practice continuum (Wachtel, 2013), which includes both preventative and reactive application of the framework. Philosophies rooted in RJ have been specifically indicated as an effective structural catalyst with potential to improve school culture and resulting climate through the strengthening of relationships within the diverse communities and the creation of more equitable educational support systems (Ingraham et al., 2016). Scholars who specialize in RJ application with respect to school settings have conceptualized RJ within an ecological framework, to account for the diversity of applications and practices throughout the multiple tiers of school support systems (Song and Swearer, 2016). The continuum of RJ strategies ranges from universal usage of restorative language (e.g., affective statements) to using formal conferencing circles in response to serious offenses (Wachtel, 2013). While there is still a significant research gap and a great deal of scholarly disagreement about how RJ philosophies should be labeled and operationalized within school practice and research (Song and Swearer, 2016), comprehensive SEL approaches that include RJ components have strong potential to improve student outcomes and contribute to school cultures that are more inclusive and connected (Haymovitz et al., 2018). Further, experts recommend that comprehensive support systems that include both SWPBS and SEL elements are optimal for improved student outcomes and school climate (Bradshaw et al., 2014).

\section{Knowledge Discussion}

As evidenced throughout the discussion of knowledge work that is currently commonplace throughout our school systems and within the literature, there is a strong foundation upon which the IPPL can enhance systems change efforts. We argue that the Knowledge quadrant, when operating independently from the other peace leadership quadrants, has not been successful in creating sustainable systems change within schools. While a critical element of organizational progress, knowledge development must be nestled within a cohesive and collaborative culture of leadership for maximum benefit to a school community. In addition, while school communities tend to be most comfortable with the concepts and general processes of knowledge building, there continues to be a gap in implementation outcomes (Kincaid et al., 2007) and a lag in abandoning school practices that have been discredited (Skiba, 2014; Smith, 2015). Whether this gap is due to resistance to new ideas or systemic implementation challenges or a combination of both is unclear. Given the reality that most school-wide socialemotional and behavioral prevention systems are implemented alongside competing efforts, such as academics (Turri et al., 2016), it is important for these knowledge components to be embedded cohesively into school culture and organizational habits. As school-wide supports are most effective when operative within a well-established MTSS framework, intentional efforts must be made to consistently make systematic connections between all efforts. For example, if conflict resolution is a topic of focus in SEL programming, it can be embedded in Language Arts curricula or interventions by choosing relevant topics and themes for students to read and write about. This type of depth creates continuous opportunities for both students and school leaders to reflect and discuss these important issues.

\section{Role of PLAG}

What is clear is that it would be essential to have an institutionalized leadership group, such as the PLAG, to help increase the generalization of knowledge work that is done throughout the school. In this role, the PLAG can work to ensure that all school leaders and personnel are trained and engaged in the collaborative knowledge efforts occurring at the school. Efforts to increase staff commitment and buy-in will be an essential piece in both this knowledge work, and the work in the other areas. The PLAG can ensure a grassroots, bottomup approach that takes into account school leader interests and concerns, ensuring that the work has broad ownership and implementation throughout the various school tiers and contexts. The PLAG can also make sure the schools efforts are systematic and purposeful as congruent with the research on social and emotional programming implementation.

\section{CULTIVATING COMMUNITIES}

The Communities quadrant provides space for collective movements and action around issues of peace and leadership. 
This is the space where new communities are built, and existing communities are further fostered. These communities should be inclusive of a variety of people and viewpoints-not only like-minded individuals. These communities serve to recognize the dignity of, and build relationships with, all people who are stakeholders in the work-even those who may be actively working against any peace and leadership efforts. This quadrant would include explicit efforts and processes to improve professional cultures through increased opportunities for collaboration and collegiality.

In a school, "communities" refer to groups within the school and those surrounding the school, such as formal and informal teacher organizations, staff member groups, student organizations, and parental groups. The communities' work may also include those community members that overlap with communities in the school, including local government officials, business owners, and non-parent neighbors. It also captures the overarching school community in which the various community groups interact and combine as a larger contextual system, as discussed by Bronfenbrenner (1992). Overarching practices that support this work include: relationship building; coalition building; building social and human capital; trust building; engaging in adaptive leadership practices; fostering diversity; creating spaces for, and of, compassion; and embracing the leadership spirit (McIntyre Miller, 2017). For the purposes of this school-based discussion, we will highlight the common community building practices of professional learning communities and the home-school connection to illustrate how the IPPL may serve to strengthen these efforts.

\section{Professional Learning Communities}

Moving beyond the more familiar and quantifiable concepts within the knowledge quadrant, the Communities quadrant captures the collective and relational aspects of how school leaders may engage in peaceful cultural and systems change. Many educators recognize Professional Learning Communities (PLC) as a way to create collaborative group structures for planning, decision-making, reflection on practice, and continuous professional development (Servage, 2008). The common use of PLCs in school staff cultures is a positive sign that community building and collaboration, essential to the IPPL, is a valued practice.

Some schools choose to structure PLC groupings by grade level and some by subjects taught. Regardless of group makeup, scholars who study PLCs posit that there are several core essential characteristics within which this practice is rooted. Theoretically, the essential characteristics of PLC include shared goals focused in concrete outcomes, collective focus on student learning, reflective dialogue, collaboration and active participation, leadership, structured and guided activities having a relation to practice, trust, geographical and organizational boundaries, stakeholder support, and individual prior knowledge and motivation (Prenger et al., 2017). However, it is rare that school leaders are intimately familiar with these characteristics and/or are adequately prepared to facilitate, self-monitor, or guide others through PLCs that embody these various qualities (Humada-Ludeke, 2013). As such, PLCs tend to be underutilized as a critical learning and community building tool that can greatly improve the connectedness between the various elements of professional development processes. In this view, effective PLCs are important elements of sustainable capacity building and systems change efforts (Voelkel and Chrispeels, 2017). As PLCs are a common practice in most schools today, the intentional community building focus of the IPPL has strong potential to strengthen these existing structures and maximize their impact on professional culture and, ultimately, on student supports.

\section{Home-School Connection}

In addition to within-school community building efforts, the fostering of strong and healthy connections between school and homes is another important factor in sustainable systems change. The research surrounding the positive correlations between parental involvement and student learning outcomes is generally consistent (Ma et al., 2016) and provides strong empirical support for the intentional community building processes between families and school leaders. The value of developing positive home-school connections is common to school districts and can often be seen in mission statements and embedded throughout various educator and leadership training programs. In addition to educator and policy driven efforts, the Parent Teacher Association (PTA) is a national organization that has been influential in schools for over a century and is dedicated to strengthening connections between schools, families, and communities. The organization website provides a plethora of resources to help schools and parent volunteers develop healthy PTAs that follow a set national standards (Parent Teacher Association, 2009), which include considerations for inclusion and supporting the needs of underserved families. This, again, provides another existing school structure from which IPPL can provide nurturing support. However, due to the heterogeneous PTA groupings across the country, it is difficult to measure how effective or inclusion all group partnerships actually are.

While healthy home-school connections are important for students of all cultural and linguistic backgrounds, there is increasing evidence that these relationships may be more difficult to foster with families with low socioeconomic status and/or whose home language is not congruent with that of the dominant school culture (McCarthey, 2000; Linse, 2011). As valuable as organizations such as the PTA can be, they are not necessarily accessible to families who are not able to commit the time for involvement or those parents who have language barriers. As a result, many families are systemically (albeit often unintentionally) excluded from the opportunities and benefits of home-school connections (Linse, 2011). Further complicating this collective goal of increasing home-school connection is the variance in the interpretations and expectations of healthy homeschool connections across cultures. Within the scope of the IPPL, increased awareness among school leaders about personal assumptions and biases in addition to the cultures and needs within their unique student and family populations (building from the Innerwork and Knowledge processes) are important first steps to cultivating healthy and productive relationships across the home and school contexts. Fortunately, there are often existing structures in most schools (e.g., community liaisons, 
PTA, etc.) from which school leaders may build on to assess the health of their home-school connections and work with parent leaders to improve practices and create more inclusive climates.

\section{Communities Discussion}

In many ways, the Communities quadrant of the IPPL, as it relates to schools, may be conceptualized as connective tissue between the various quadrants in that it is the collective synergy needed to sustain the ongoing innerwork and knowledge building that is required for effective systems improvement, and sets the stage for larger systems work. As educational institutions are in a constant state of growth and change in terms of practice and structure, the strength of connections within and between the various intersecting communities may determine the quality of relationships and overarching school culture. Community building activities are valuable spaces where structured dialogue can be safely and regularly facilitated to share concerns, celebrate success, process conflicts, challenge belief systems, nurture connections, and come to mutual understanding-even in the face of disagreement. The community building processes within school environments must be intentional and explicit, particularly in schools with high cultural and linguistic diversity where cultural mismatch is more likely.

\section{Role of PLAG}

Within an IPPL implementation process, the PLAG members are essential in assessing current school practices that are aimed in fostering positive community and how those processes may be strengthened. For example, it would be worthwhile to gather information about how various teams structure PLC meetings to strengthen both the professional development aspects, as well as the notion of PLC meetings being community-building processes. Using information and input from PLC participants, the PLAG can facilitate the creation of mutually agreed upon group norms and expected processes for guidance. To support healthy home-school connections, PLAG members may choose to create taxonomies to catalog current methods of parent communication and evaluate how culturally responsive these efforts are to the schools unique family populations (Linse, 2011). They may also discover creative ways to engage families through social community events (e.g., cultural fairs, food festivals, etc.) or even home visits when welcome and appropriate.

PLAG members are encouraged to use the knowledge base of restorative justice philosophies to build also community among adult stakeholders. For example, restorative circles may be used in staff meetings, parent meetings, and mixed community meetings in order to resolve conflicts, processing of crises or discipline incidences, or simply to share ideas on how to improve school practices. While research is lacking in determining the effectiveness of restorative circles with school staff, the experience with their potential benefits may increase staff buy-in and expertise in facilitating circles for students. This is an important and practical way to integrate knowledge and communities practices, and would be a worthy endeavor for schools who adopt the IPPL. As part of this integration, it would be essential to provide adequate training in best practices for PLC, home-school connections, and restorative practices for the PLAG members, particularly given the importance of internal capacity for these types of sustainable systems change (Adelman and Taylor, 2007; Song and Swearer, 2016).

\section{EXAMINING ENVIRONMENT}

The Environment quadrant is the larger space that examines the surrounding landscape of societal structures and systems involved in peace and leadership. It is where the systems and structures that work toward peace can be honored and enhanced, and those that work toward exclusion and aggression can be challenged. This quadrant holds the space for the collective work of the other quadrants to manifest itself on a larger and broader scale-including key players and systems that may not appear directly relating to the local context.

For school leaders, this requires looking at the surrounding community network beyond the district and parents. It requires critical examination of the work of other neighborhood schools, the district, the state, and the federal processes, regulations, and requirements. It includes looking at other influencing systems including university systems, the local and state government systems, and other potentially influencing areas. It includes connections such as school discipline practices and the schoolto-prison-pipeline (Smith, 2015), as well as the achievement gap for minority students (Williams, 2011), and subsequent outcomes for these groups in society. Some of the actions fostered in this quadrant include systems thinking, nonviolent social movements, advocacy and activism, networked and distributed leadership models, complexity and chaos theories, and ecoleadership (McIntyre Miller, 2017). For the purposes of this discussion, we will highlight the practices congruent with systems thinking and distributed leadership in the school context.

\section{Systems Thinking}

Systems thinking stems from the biological and ecological sciences and encourages us to think beyond the linear understandings of our world in order to appreciate the various individual and collective players that operate and function around us (Wheatley, 2006; Capra and Luisi, 2014). A systems thinking lens is particularly important for educators as our schools comprise complex and interconnected networks of individuals and groups that impact the work we do, and the students we teach (Capra and Luisi, 2014). Building on Bronfenbrenner's (1977) Ecological Systems Theory, social ecological models emphasize interpersonal and cultural elements of environments and have resulted in more interventions intended to create positive change in social relationships within organizational environments (Griffiths et al., 2009; Richard et al., 2011; Golden and Earp, 2012; Rudasill et al., 2018). Further, considering that racial and cultural elements of a school environment are socially constructed structures in themselves (Watkins and Aber, 2009), social ecological models are especially appropriate for the study and systemic change efforts directed at the gender, racial, ethnic, and ability inequities within organizations. Included in our work with schools are the direct systems in play, such as the students, parents, school leaders and staff, and broader stakeholders such as district, state, and federal actors, the communities in which our schools are embedded, local businesses who contribute to or serve our school stakeholders, 
and social services who have direct involvement. When educators approach their roles as critical parts within the larger systems, their potential impact exceeds the immediate environment and can improve even disrupt problematic social patterns within the larger societal context (Wheatley, 2006; Castells, 2010).

The application of system thinking into school environments is not new, as a plethora of research has been dedicated to both school-wide interventions to achieve systems change (e.g., professional development, SWPBIS, SEL, RJ), as well as to understand the conditions needed for effective and lasting systems change in schools (Adelman and Taylor, 2007; Astor et al., 2010; Cavendish et al., 2016; Turri et al., 2016). Furthermore, the decades of research supporting the use of MTSS and similar frameworks within schools (California Department of Education, 2017), only solidifies the need for collective systems thinking for implementation of these support structures with fidelity. Despite the consensus among school-based scholars about the importance of using systems thinking in all aspects of school operations, there continues to be a disparity between these values and their translation into common school practices. We argue that in order to make such systems change possible, school leaders must move beyond their comfort zones of individual roles and settings, and see their impact and responsibilities within the context of a broader system. Within the IPPL, systems thinking is viewed as a skill-set that requires explicit attention within professional development processes.

One hypothesis as to why common school practices lag behind the research and theories of systems and ecological perspectives is that many educators lack an adequate understanding of systems theory and how their practices actually impact systems beyond the individual student or family (Cavendish et al., 2016). Adelman and Taylor (2007) argue that most systems change efforts suffer from inadequate direct training in systems thinking and poor subsequent contextualization of the vision and skills emphasized throughout professional development. The chronic inattention to systems level variables in professional development and implementation efforts often results in making the core values and concepts less accessible to all staff involved. In other words, educators may need explicit training and learning opportunities in systemic problem and goal conceptualization to understand fully the value and processes necessary for change. Further, the ability to understand and operate within a systems thinking perspective, in addition to the development of cultural awareness, are both important factors in the actualization of culturally responsive practices (Mena and Rogers, 2017). This is another example where all four quadrants of the IPPL can work together to improve professional culture and collaborative efforts to improve systems change endeavors. Systems thinking may also occur beyond the staff development level, and into the instructional level where educators can teach their students this type of thinking (Curwen et al., in review), thus deepening the impact of the work and help develop creative problem-solving skills throughout the school.

\section{Distributed Leadership}

Distributed leadership, as envisioned in the IPPL, is another unique contribution to the conceptualization of systems change work in schools. Since one of the most common barriers to effective and sustaining systems change is the frequency in leadership turnover within schools (Turri et al., 2016; Snodgrass Rangel, 2018), it is important to consider alternative approaches to leadership empowerment and distribution within systems change efforts. New distributed and networked models of leadership no longer see a single leader at the top of a pyramid, but identify the values of sharing roles and responsibilities throughout the school (Castells, 2010, 2012). These new models of leadership become the work of a connected team to set tasks, general practices, norms, goals, expectations and the vision (Capra and Luisi, 2014), thus increasing resilience in the face of administrative turnover. Distributive models of leadership focus on building teams and team practices based on individual skill sets and providing space for people to utilize the skills at which they are most adept, while stepping back when their areas of expertise are less essential to team and school function. In other words, these are leaderful endeavors, not leaderless ones (Western, 2014). Distributed leadership teams should be flexible, fluid, and organic and ready to adapt to the changing needs of the team and the school environment (Senge, 2006). Despite limited research on the use of distributed leadership structures in schools, this area warrants further attention and consideration.

\section{Environment Discussion}

Given the reality that sustainable systems change within schools has proven challenging, the Environment quadrant of the IPPL is a necessary element in creating a comprehensive approach to conceptualizing how to go about these change efforts. Rather than focusing on how difficult or complex these systems change efforts can be, we argue that the IPPL provides an important guideline to address all the potential barriers to such efforts. It is important to avoid viewing the IPPL as another program to add to schools, but more as a jumpstart to both improve implementation efforts and ensure a culturally responsive approach. By using an ecological perspective to design and guide professional development and implementation efforts, systems change needs not be an elusive idea. If an overarching goal within a systems change effort includes a collective understanding of systems thinking, educators may be more invested and convinced of the value of their social justice oriented approaches.

\section{Role of PLAG}

The PLAG can also serve as a means to encourage and enhance system thinking in the school. By being inclusive of operators in many systems within the school, including students, teachers, administrators, and staff, the PLAG serves as a model to bring people together and purposefully understand the needs and values of each system. This will pave the way to broader systems understanding including systems outside, but affiliated with, the school. The PLAG can serve as a catalyst for augmenting these relationships and bringing representatives of these systems together for broader understanding and increased involvement. The PLAG can help encourage all school leaders to think beyond traditional school boundaries and reframe the way the school connects with the various stakeholders necessary to create the 
kind of peaceful school culture that sustains long-term positive change.

As with efforts in the other quadrants, the PLAG has an essential role to play in implementing the environment aspect of peace leadership work for cultural and systemic change. In many ways, the PLAG can serve to model the functioning of a distributive team. Utilizing the practices of networked leadership, the team can ensure that responsibilities are shared and that members are building on their strengths when appropriate, and taking a back seat to others when not. By modeling distributive leadership in the PLAG, members can encourage distributive leadership in the PLCs and other school-based teams. Often seeing others being successful in this model is inspiration for those who also may engage in the work.

\section{CONCLUSIONS AND IMPLICATIONS}

As illustrated throughout this paper, the IPPL offers a comprehensive framework to guide sustainable systems and cultural change efforts within schools. Despite decades of research on school climate and systems change efforts to improve both student outcomes and experiences, there remains to an urgent need for improvement of implementation processes (Adelman and Taylor, 2007). As more schools and districts continue to adopt MTSS frameworks to enhance their effectiveness in meeting the needs of all students, the discussion of how to approach systems change in a comprehensive and inclusive fashion is important and timely. In the preceding pages, we argue that peace leadership may be a useful vehicle that weaves together existing and congruent practices and build the capacity of school leaders to effectively cultivate a positive, inclusive, and even peaceful school culture. This collaborative and cohesive approach to systems change, with its focus on social justice and equitable practice, makes the IPPL an ideal fit for school leaders to consider in their change efforts.

Building from existing practices is essential, as schools are already taking steps, and investing significant resources, to bring about cultural change. As we suggest throughout our analysis, challenges in systems change arise when these efforts are not meaningfully integrated, and do not involve efforts in all four areas of Innerwork, Knowledge, Communities, and Environment. The IPPL provides a unique organizational framework that may offer some solutions to some barriers in the cultural change process-through thoughtful program evaluation of existing efforts, strengthening ongoing system change efforts, and ensuring that these efforts are nurtured throughout all four levels in an inclusive and cohesive way. The adoption of the IPPL for systems change support requires that school leaders understand the concepts and related activities of all four quadrants, and can work toward creating comprehensive professional development designs that provide continuous opportunities for practice, learning, collaboration, and reflection in every area. It is also important for school leaders who wish to integrate the IPPL into their school cultures to appreciate that, like any systems change effort, this process is not time-limited and requires permanent and evolving shifts in attitudes and practices to achieve desired outcomes.

While most school-wide support systems generally and logically involve more student-centered approaches, we argue that effective systems change must also incorporate thoughtful and intentional processes that are focused on building skills and capacity within the school leaders tasked with the most critical elements of implementation. It is possible that school administrators and researchers have been operating with many assumptions about how well equipped all educators are to implement proposed school-wide interventions, particularly with an understanding of systems and culturally responsive practices. Therefore, we argue that the IPPL may offer strong guiding principles to inform effective professional development for school leaders that not only increase skills, but also may serve to create professional cultures of awareness, collaboration, and collective energy toward creating more peaceful and equitable environments.

An encouraging point to remember when considering the adoption of IPPL as a systems change guide is that many educators already value and embody many of the peace leadership characteristics we have described throughout this paper. Based on our experiences in both schools and higher education programs, educators often enter the profession with some passion for social change, and have genuine desires to make a positive difference in the world through their work with students and families. This innate quality that is common among educators can be nurtured and multiplied with the right environmental and professional supports. In addition, school counselors and school psychologists are valuable internal consultative assets to the IPPL efforts as the professions are typically framed within social justice and effective change agent perspectives (Shriberg et al., 2008; McMahon et al., 2009; Ingraham, 2015). The realization that most of our schools already have natural peace leaders operating within them is hopeful in that comprehensive IPPL integration may build on these existing leadership strengths to facilitate greater momentum in this direction. However, since not all school leaders will naturally lean toward the inherent principles of the IPPL, it is beneficial to focus on areas of common values and goals, such as improved student behavior and positive professional cultures. While it is important for school leaders with the most power and authority to approach systems change with an IPPL lens, it is equally as important to empower all school leaders to take active and meaningful roles within systems change efforts. IPPL leaders and advocates should approach this endeavor with the nonjudgmental understanding that everyone will enter this process at different starting points and will ultimately experience unique developmental journeys.

\section{Review of PLAG}

As implementation teams are usually critical components to any systems change effort (Jenlink et al., 1998; Adelman and Taylor, 2007), we have suggested the creation of a Peace Leadership Advisory Group (PLAG). A strong core leadership team is essential for the implementation of the IPPL in schools. The PLAG provides the direction of the school activities for systemic 
and cultural change and maintains accountability. Throughout each of the sections above, we have suggested ways in which the PLAG might be a crucial connective and collaborative element to bring about change in the areas of Innerwork, Knowledge, Community, and Environment as most appropriate within any unique school culture. Table 1 summarizes these potential PLAG actions for an understanding of involvement at each level. It is important to note that Table $\mathbf{1}$ aims to be merely suggestive, rather than prescriptive or exhaustive, as school sites may opt to choose the practices that are most suitable for their cultural and systemic needs.

Implementing the IPPL in the ways suggested in Table 1 requires resources from both the school leaders and the supporting district leaders. Many of the necessary resources, however, may not extend far beyond those already allotted for other systems change efforts (i.e., MTSS). Since the IPPL is not intended to be a new program, but rather a reframing and enhancement of existing programs, associated actions should be integrated into current practice where it can then become a transformative catalyst for positive change. The following list provides examples of structural and systemic resources, which may also be conceptualized as the role of district-level peace leaders, that are needed to support the efforts of the PLAG team and other school-level peace leaders. Required resources may include: (1) Provision of consultation supports and training (e.g., SWPBIS, SEL, cultural responsive practices, restorative justice, etc.), (2) Release time for PLAG team members from other duties, (3) Space for meeting and interacting, (4) Access to school communication resources and technologies, (5) Access to highquality training for all personnel, and (6) Resources for supplies (e.g., rewards, curricula, etc.). Building from these resources and opportunities, the implementation of the IPPL in schools have multiple positive implications for systemic and culture change.

\section{Implications for Building Peace and Reducing Violence}

There are several important implications of implementing the IPPL in schools as a method of systematic and cultural change. First, the integration of peace leadership concepts into systems work within schools is incredibly relevant as researchers continue to explore methods to reduce violence, increase connection in school communities, and improve school-wide implementation efforts. Galtung (1996) discussed the importance of understanding peace as both positive, that which focuses on building positive social structures, and negative, that which focuses on challenging aggression and violence. Throughout the discussion of common social-emotional and behavioral practices, we demonstrated that the upward direction of school-based research and practice toward positive, inclusive, and ecologically designed systems change efforts is well aligned with the central tenets of the IPPL. Given that many schools have already begun these compatible practices, the IPPL may work in harmony to strengthen these efforts and build on this momentum. By accounting for the complexities in leadership development and community connection, the IPPL provides a useful lens through which all key elements of systems change are acknowledged and attended to.

\section{Implications for Professional Development}

The IPPL model has significant implications for professional training programs and ongoing professional development

TABLE 1 | PLAG Actions and Necessary Structures and Systems.

Element Examples of PLAG actions

Innerwork (e.g., mindfulness and character education)

- Conduct needs assessment to gather information about staff perspectives and skill levels

- Develop simple progress monitoring methods

- Develop an innerwork action plan

- Engage in professional learning, practice, and discussion

- Initiate regular communication and encouragement (e.g., in person, email communications/resources)

- School counselors or school psychologists consult for staff, admin, and parents as needed

- Focus on consistent character traits for students and staff (e.g., choose one trait a month and cover/discuss in PD and classroom lessons)

- Facilitate consistent opportunities for regular reflection on how school leaders personally model and/or embody innerwork

Knowledge (e.g., school-wide positive behavior supports and social-emotional learning)
- Create taxonomies of existing programming and resources

- Train all personnel in Knowledge efforts occurring at the school (e.g., ensure all staff engage in PBIS efforts)

- Facilitate relevant and cohesive PLC processes that are intentional and collaborative

- Provide staff reinforcement and additional learning opportunities that ensure broad ownership of Knowledge-based activities

- Ensure efforts are systematic and purposeful through progress monitoring of student outcomes and staff perceptions

- Assess existing school practices that build community within various school contexts (e.g., classrooms, staff meetings, etc.) - Create mutually - agreed upon group norms and expectations for building community within the school and at home

Communities (e.g., professional learning communities and home-school connection)
- Assess current communication with parents and guardians for cultural responsiveness (e.g., home communication taxonomies)

- Assess ability to engage communities with social events (e.g., cultural fairs, food festivals, etc.)

- Build capacity for restorative circles to use within the community (e.g., training and spaces for practice)
Environment (e.g., systems thinking and distributed leadership)
- Collect and consider perspectives and needs from all stakeholders, including students, teachers, administrators, and staff - Collaborate with surrounding systems, including business owners, local government, and affiliated programs and nonprofits

- Can model the work of a distributed team by sharing responsibilities based on strengths and expertise 
for future and current school leaders. As central to child developmental contexts nested within our society, our school leaders have a crucial responsibility to foster safe and inclusive environments for all students to learn and grow. With coursework and training opportunities designed to develop peace leadership potential, future school leaders may enter the field with strong foundations in social justice, advocacy, and systems-thinking perspectives. When these core concepts are meaningfully and practically embedded throughout foundational training and professional learning opportunities, positive movement toward cultural change is more likely. Although it is unrealistic to suggest that every school leader will enthusiastically embrace the philosophies that underlie the IPPL, the more school leaders who are actively engaged in and surrounded by this work, the larger impact can be made within the school, and in broader contexts.

\section{Implications for Creating a Culture of Peace}

Lastly, utilizing the IPPL in schools enables us to further the efforts of creating a culture of peace in our world, as

\section{REFERENCES}

Adelman, H. S., and Taylor, L. (2007). Systematic change for school improvement. J. Educ. Psychol. Consult. 17, 55-77. doi: 10.1080/10474410709336590

Adler, N. J. (1998). "Societal leadership: the wisdom of peace," in Organizational Change and Executive Wisdom, eds S. Srivastva and D. L. Cooperrider (San Francisco, CA: The New Lexington Press), 205-221.

Amadalas, S. (2018). "The intentional leadership of Mohandas Gandhi," in Peace Leadership: The Quest for Connectedness, eds S. Amadalas and S. Byrne (New York, NY: Routledge), 46-61.

Arcia, E. (2006). Achievement and enrollment status of suspended students: outcomes in a large, multicultural school district. Educ. Urban Soc. 38, 359-369. doi: $10.1177 / 0013124506286947$

Astor, R. A., Guerra, N., and Van Acker, R. (2010). How can we improve school safety research? Educ. Res. 39, 69-78. doi: 10.3102/0013189X09357619

Baer, R. A. (2003). Mindfulness training as a clinical intervention: a conceptual and empirical review. Clin. Psychol. Sci. Pract. 10, 125-143. doi: 10.1093/clipsy.bpg015

Banks, T., and Obiakor, F. E. (2015). Culturally responsive positive behavior supports: considerations for practice. J. Educ. Training Stud. 3, 83-90. doi: 10.11114 /jets.v3i2.636

Bayar, A. (2014). The components of effective professional development activities in terms of teachers' perspective. 6, 319-327. doi: 10.15345/iojes.2014.02.006

Bear, G. G., Yang, C., and Pasipanodya, E. (2015). Assessing school climate validation of a brief measure of the perceptions of parents. J. Psychoeduc. Assess. 33, 115-129. doi: 10.1177/0734282914545748

Boyer, P. (1986). Peace leaders, internationalists, and historians: some reflections. Peace Change 11, 93-104.

Bradshaw, C. P., Bottiani, J., Osher, D., and Sugai, G. (2014). "The integration of positive behavioral interventions and supports and social and emotional learning," in Handbook of School Mental Health, eds M. Weist, N. Lever, C. Bradshaw, and J. Owens (New York, NY: Springer), 101-118.

Bradshaw, C. P., Koth, C. W., Bevans, K. B., Lalongo, N., and Leaf, P. J. (2008). The impact of school-wide positive behavioral interventions and supports (PBIS) on the organizational health of elementary schools. School Psychol. Quart. 23, 462-473. doi: 10.1037/a0012883

Bronfenbrenner, U. (1977). Toward an experimental ecology of human development. Am. Psychol. 32, 513-531. doi: 10.1037/0003-066X.32.7.513
Schellhammer (2018) argues. After all, efforts of peace leadership and cultural and systems change in our schools is to create a world that honors equity, justice, and inclusion - where all school participants are welcome and encouraged to be leaderful. As a systems change model in itself, the IPPL would ideally be applied throughout multiple contexts of society (e.g., homes, schools, businesses, government, etc.) to continue planting seeds of peace and justice within our own communities and throughout the globe. The application of IPPL to the school setting, and beyond, is inherent to the systems and ecological foundations of the model itself. When peace leaders throughout all contexts collectively work toward this greater good; we move closer to a reality where we no longer have to worry about efforts of negative peace because we are so busy living in a world and culture of positive peace (Galtung, 1996).

\section{AUTHOR CONTRIBUTIONS}

Both authors provided equally to this manuscript. WM provided the information on peace leadership and literature, and AA provided the school-based examples and literature.

Bronfenbrenner, U. (1992). "Ecological systems theory," in Six Theories of Child Development: Revised Formulations and Current Issues, ed R. Vasta (London: Jessica Kingsley), 187-249.

Burke, C. A. (2010). Mindfulness-based approaches with children and adolescents: a preliminary review of current research in an emergent field. J. Child Family Studies 19, 133-144. doi: 10.1007/s10826-009-9282-x

California Department of Education (2017). California Department of MultiTiered Systems of Support. Available online at: https://www.cde.ca.gov/ci/cr/ri/ mtsscomprti2.asp

Capra, F., and Luisi, P. L. (2014). The Systems View of Life: A Unifying Vision. Cambridge: Cambridge University Press.

CASEL. (2013). Collaborative for Academic, Social, and Emotion CASEL Guide: Effective Social and Emotional Learning Programs. Available online at: https:// casel.org/preschool-and-elementary-edition-casel-guide

Castells, M. (2010). The Rise of the Network Society, 2nd Edn. West Sussex: Wiley-Blackwell.

Castells, M. (2012). Networks of Outrage and Hope: Social Movements in the Internet Age. Cambridge, CA: Polity Press.

Cavendish, W., Harry, B., Menda, A., Espinosa, A., and Mahotiere, M. (2016). Implementing response to intervention: challenges of diversity and system change in a high-stakes environment. ERIC 118, 1-36.

Chappell, P. (2013). The Art of Waging Peace: A Strategic Approach to Approving Our Lives and the World. Westport, CT: Prospecta Press.

Chinn, P., and Falk-Rafael, A. (2018). "Critical caring as a requisite for peace leadership," in Peace Leadership: The Quest for Connectedness, eds S. Amadalas and S. Byrne (New York, NY: Routledge), 195-211.

Colorado State Department of Education (2000). "Shaping the future through character education," in Colorado State Conference on Character Education (Denver, CO). Available online at: https://files.eric.ed.gov/fulltext/ED468627. pdf

Curtis, M. J., and Stollar, S. A. (2002). "Best practices in system-level change," in Best Practices in School Psychology IV, eds A. Thomas and J. Grimes (Washington, DC: National Association of School Psychologists), 223-234.

Dessel, A. (2010). Prejudice in schools: promotion of an inclusive culture and climate. Educ. Urban Soc. 42, 407-429. doi: 10.1177/0013124510361852

Dinan, B. A. (2012). "Ubuntu leadership," in Paper presented at the Barrett ValuesBased Leadership Conference (Cape Town). 
Dinan, B. A. (2018). "Conscious peace leadership: examining the leadership of Mandela and Sri Aurobindo," in Peace Leadership: The Quest for Connectedness, eds S. Byrne and S. Amadalas (New York, NY: Routledge), 107-121.

Dodge, K. A., Coie, J. D., and Lynam, D. (2006). "Aggression and antisocial behavior in youth," in Handbook of Child Psychology, eds W. Damon and R. M. Lerner (Hoboken, NJ: John Wiley and Sons Inc.), 437-461.

Durlak, J. A., Weissberg, R. P., Dymnicki, A. B., Taylor, R. D., and Schellinger, K. B. (2011). The impact of enhancing students' social and emotional learning: a meta-analysis of school-based universal interventions. Child Dev. 82, 405-432. doi: 10.1111/j.1467-8624.2010.01564.x

Dweck, C. S. (2006). Mindset: The New Psychology Of Success. New York, NY: Random House.

Elias, M. J., and Moceri, D. C. (2012). Developing social and emotional aspects of learning: the American experience. Res. Pap. Educ. 27, 423-434. doi: 10.1080/02671522.2012.690243

Espinoza, G., and Juvonen, J. (2011). Perceptions of the school social context across the transition to middle school: heightened sensitivity among Latino students. J. Educ. Psychol. 103, 749-758. doi: 10.1037/a0023811

Fan, W., Williams, C. M., and Corkin, D. M. (2011). A multilevel analysis of student perceptions of school climate: the effect of social and academic risk factors. Psychol. Sch. 48, 632-647. doi: 10.1002/pits.20579

Felver, J. C., Doerner, E., Jones, J., Kaye, N. C., and Merrell, K. W. (2013). Mindfulness in school psychology: applications for intervention and professional practice. Psychol. Schools 50, 531-547. doi: 10.1002/pits.21695

Fenning, P., and Rose, J. (2007). Overrepresentation of African American students in exclusionary discipline the role of school policy. Urban Educ. 42, 536-559. doi: $10.1177 / 0042085907305039$

Galtung, J. (1996). Peace by Peaceful Means: Peace and Conflict, Development, and Civilization. Los Angeles, CA: Sage Publications.

Ganz, M. (2010). "Leading change: leadership, organization, and social movements," in Handbook of Leadership Theory and Practice, eds N. Nohria and R. Khurana, (Cambridge, MA: Harvard Business Press), 509-550.

Golden, S. D., and Earp, J. A. (2012). Social ecological approaches to individuals and their contexts: twenty years of health education \& behavior health promotion interventions. Health Educ. Behav. 39, 364-372. doi: $10.1177 / 1090198111418634$

Goulah, J., and Urbain, O. (2013). Daisaku Ikeda's philosophy of peace, education proposals, a Soka education: convergences and divergences in peace education. J. Peace Educ. 103, 303-322. doi: 10.1080/17400201.2013.848072

Gregory, A., Skiba, R. J., and Noguera, P. A. (2010). The achievement gap and the discipline gap: two sides of the same coin? Educ. Res. 39, 59-68. doi: 10.3102/0013189X09357621

Griffiths, A. J., Sharkey, J. D., and Furlong, M. J. (2009). "Student engagement and positive school adaptation," in Handbook of Positive Psychology in Schools, eds R. Gilman, E. S. Huebner, and R. M. Furlong (New York, NY: Routledge), 197-211.

Grossman, P., Niemann, L., Schmidt, S., and Walach, H. (2004). Mindfulnessbased stress reduction and health benefits: a meta-analysis. J . Psychosomatic Res. 57, 35-43. doi: 10.1016/S0022-3999(03)00573-7

Harber, C., and Davies, L. (2003). "Effective leadership for war and peace," in Leadership in Education, eds M. Brundrett, N. Burton, and C. Smith (London: Sage Publications), 132-146.

Haymovitz, E., Houseal-Allport, P., Scott Lee, R., and Svistova, J. (2018). Exploring the perceived benefits and limitations of a school-based socialemotional learning program: a concept map evaluation. Child. Sch. 40, 45-53. doi: $10.1093 / \mathrm{cs} / \mathrm{cdx} 029$

Hofmann, S. G., Sawyer, A. T., Witt, A. A., and Oh, D. (2010). The effect of mindfulness-based therapy on anxiety and depression: a meta-analytic review. J. Consult. Clin. Psychol. 78, 169-183. doi: 10.1037/a0018555

Horner, R. H., and Sugai, G. (2015). School-wide PBIS: an example of applied behavior analysis implemented at a scale of social importance. Behav. Analysis Practice 8, 80-85. doi: 10.1007/s40617-015-0045-4

Humada-Ludeke, A. (2013). The Creation of a Professional Learning Community for School Leaders: Insights on the Change Process From the Lens of the School Leader. Rotterdam: Springer Science and Business Media.

Hyman, I., Cohen, I., and Mahon, M. (2003). Student alienation syndrome: A paradigm for understanding the relation between school trauma and school violence. California School Psychol. 8, 73-86. doi: 10.1007/BF03340897
Ingraham, C. L. (2015). Competencies for systems-level consultants within diverse schools. J. Educ. Psychol. Consult. 25, 148-159. doi: 10.1080/10474412.2014.963227

Ingraham, C. L., Hokoda, A., Moehlenbruck, D., Karafin, M., Manzo, C., and Ramirez, D. (2016). Consultation and collaboration to develop and implement restorative practices in a culturally and linguistically diverse elementary school. J. Educ. Psychol. Consult. 26, 354-384. doi: 10.1080/10474412.2015. 1124782

Jenlink, P. M., Reigeluth, C. M., Carr, A. A., and Nelson, L. M. (1998). Guidelines for facilitating systemic change in school districts. Syst. Res. Behav. Sci. 15, 217-233. doi: 10.1002/(SICI)1099-1743(199805/06)15:3<217::AIDSRES223 $>3.0 . C O ; 2-\mathrm{N}$

Jennings, G. (2003). An exploration of meaningful participation and caring relationships as contexts for school engagement. California School Psychol. 8, 43-51. doi: 10.1007/BF03340895

Karp, D. R., and Breslin, B. (2001). Restorative justice in school communities. Youth Soc. 33, 249-272. doi: 10.1177/0044118X01033002006

Kataoka, S. H., Zhang, L., and Wells, K. B. (2002). Unmet need for mental health care among U.S. children: variation by ethnicity and insurance status. Am. J. Psychiatry 159, 1548-1555. doi: 10.1176/appi.ajp.159.9.1548

Kincaid, D., Childs, K., Blase, K. A., and Wallace, F. (2007). Identifying barriers and facilitators in implementing schoolwide positive behavior support. J. Positive Behav. Interv. 9, 174-184. doi: 10.1177/10983007070090030501

Ledbetter, B. (2012). Dialectics of leadership for peace: toward a moral model of resistance. J. Leadership Account. Ethics 9, 11-24.

Ledbetter, B. (2016). Business leadership for peace. Int. J. Public Leadersh. 12, 239-251. doi: 10.1108/IJPL-04-2016-0016

Lickona, T. (1997). The teacher's role in character education. J. Educ. 179, 63-80. doi: 10.1177/002205749717900206

Lieberfeld, D. (2009). Lincoln, Mandela, and qualities of reconciliationoriented leadership. Peace Conflict J. Peace Psychol. 15, 27-47. doi: 10.1080/10781910802589857

Lieberfeld, D. (2011). Reconciliation-oriented leadership: Chilean president Michelle Bachelet. Peace Conflict J. Peace Psychol. 17, 303-325. doi: 10.1080/10781919.2011.560858

Lindahl, R. A. (2011). The crucial role of assessing the school's climate and culture in planning for school improvement. Educ. Planning 20, 16-30.

Linse, C. T. (2011). Creating taxonomies to improve school-home connections with families of culturally and linguistically diverse learners. Educ. Urban Soc. 43, 651-670. doi: 10.1177/0013124510380908

Ma, X., Shen, J., Krenn, H. Y., Hu, S., and Yuan, J. (2016). A meta-analysis of the relationship between learning outcomes and parental involvement during early childhood education and early elementary education. Educ. Psychol. Rev. 28, 771-801. doi: 10.1007/s10648-015-9351-1

Marx, S., and Byrnes, D. (2012). Multicultural school climate inventory. Curr. Issues Educ. 15. Available online at: https://cie.asu.edu/ojs/index.php/cieatasu/ article/view/960

Matesi, L. (2013). Vision and Foresight as Narrated by Nobel Peace Laureates, Unpublished Dissertation, Gonzaga University, Gonzaga, WA.

McCarthey, S. J. (2000). Home-school connections: a review of the literature. J. Educ. Res. 93, 145-153. doi: 10.1080/00220670009598703

McIntyre Miller, W. (2016). Toward a scholarship of peace leadership. Int. J. Public Leadersh. 12, 216-226. doi: 10.1108/IJPL-04-2016-0013

McIntyre Miller, W. (2017). Peace Leadership Development Curriculum. Available online at: http://peaceleadershipcollaborative.org/peace-leadershipdevelopment-curriculum/introduction/

McIntyre Miller, W., and Green, Z. (2015). An integral perspective of peace leadership. Integr. Leadersh. Rev. 15. Available online at: http:// integralleadershipreview.com/12903-47-an-integral-perspective- of-peaceleadership/

McIntyre Miller, W., and Wunduh, M. (2015). Peace profile: Christiana Thorpe. Peace Rev. 27, 515-521. doi: 10.1080/10402659.2015.1094347

McMahon, G., Mason, E. C. M., and Paisley, P. O. (2009). School counselor educators as educational leaders promoting systemic change. Professional School Counsel. 13, 116-124. doi: 10.5330/PSC.n.2010-13.116

Mena, J. A., and Rogers, M. R. (2017). Factors associated with multicultural teaching competence: social justice orientation and multicultural 
environment. Train. Educ. Profess. Psychol. 11, 61-68. doi: 10.1037/tep 0000143

Mendenhall, A. N., Iachini, A., and Anderson-Butcher, D. (2013). Exploring stakeholder perceptions of facilitators and barriers to implementation of an expanded school improvement model. Children School 53, 225-234. doi: $10.1093 / \mathrm{cs} / \mathrm{cdt} 011$

Meyers, A. B., Meyers, J., Graybill, E. C., Proctor, S. L., and Huddleston, L. (2012). Ecological approaches to organizational consultation and systems change in educational settings. J. Educ. Psychol. Consult. 22, 106-124. doi: 10.1080/10474412.2011.649649

Minkos, M. L., Sassu, K. A., Gregory, J. L., Patwa, S. S., Theodore, L. A., and Femc-Bagwell, M. (2017). Culturally responsive practice and the role of school administrators. Psychol. Schools 54, 1260-1266. doi: 10.1002/pits. 22072

Mitchell, M. M., and Bradshaw, C. P. (2013). Examining classroom influences on student perceptions of school climate: the role of classroom management and exclusionary discipline strategies. J. School Psychol. 51, 599-610. doi: $10.1016 /$ j.jsp.2013.05.005

Netzel, D. M., and Eber, L. (2003). Shifting from reactive to proactive discipline in an urban school district: a change of focus through PBIS implementation. J. Positive Behav. Interv. 5, 71-79. doi: 10.1177/109830070300500 20201

Ngunjiri, F. W. (2010). Women's Spiritual Leadership in Africa: Tempered Radicals and Critical Servant Leaders. Albany, NY: SUNY Press.

Osher, D., Bear, G. G., Sprague, J. R., and Doyle, W. (2010). How can we improve school discipline? Educ. Res. 39, 48-58. doi: 10.3102/0013189X09357618

Pacific Integral (2003). Introduction to Integral Theory and Practice: IOS Basic and the AQAL Map. Available online at: http://www.pacificintegral.com/docs/ integralsummary.pdf

Parent Teacher Association (2009). PTA National Standard for Family-School Partnerships: An Implementation Guide. Available online at: https://s3. amazonaws.com/rdcms-pta/files/production/public/National_Standards_ Implementation_Guide_2009.pdf

Prenger, R., Poortman, C. L., and Handelzalts, A. (2017). Factors influencing teachers' professional development in networked professional learning communities. Teach. Teach. Educ. 68, 77-90. doi: 10.1016/j.tate.2017.08.014

Reychler, L., and Stellamans, A. (2005). Researching Peace Building Leadership: Cahier of the Center for Peace Research and Strategic Studies (CPRS). Diplomatic Thinking. Available online at: https://irias.kuleuven.be/bitstream/123456789/ 400526/1/Cahier71_ReychlerStell

Richard, L., Gauvin, L., and Raine, K. (2011). Ecological models revisited: their uses and evolution in health promotion over two decades. Ann. Rev. Public Health 32, 307-326. doi: 10.1146/annurev-publhealth-031210-101141

Rudasill, K., Snyder, K. E., Levinson, H., and Adelson, J. L. (2018). Systems view of school climate: a theoretical framework for research. Educ. Psychol. Rev. 30, 35-60. doi: 10.1007/s10648-017-9401-y

Rutherford, C. (2006). Teacher leadership and organizational structure: the implications of restructured leadership in an Edison School. J. Educ. Change 7, 59-72. doi: 10.1007/s10833-006-0013-4

Sarsar, S. (2008). Reconceptualizing peace leadership: the case of Palestinian-Israeli relations. Int. Leadersh. J. 1, 24-38.

Schellhammer, E. (2016). A culture of peace leadership education. Int. J. Public Leadersh. 12, 205-215. doi: 10.1108/IJPL-04-2016-0014

Schellhammer, E. (2018). “Authentic peace leadership," in Peace Leadership: The Quest for Connectedness, eds S. Amadalas and S. Byrne (New York, NY: Routledge), 75-91.

Shriberg, D., Bonner, M., Sarr, B. J., Walker, A. M., Hyland, M., and Chester, C. (2008). Social justice through a school psychology lens: definition and applications. Sch. Psychol. Rev. 37, 453-468.

Senge, P. (2006). The Fifth Discipline. New York, NY: Doubleday.

Servage, L. (2008). Critical and transformative practices in professional learning communities. Teacher Educ. Quart. 35, 63-77.

Skiba, R. J. (2014). The failure of zero tolerance. Reclaiming Children Youth 22, 27-33.

Skiba, R. J., Horner, R. H., Chung, C. G., Rausch, M. K., May, S. L., and Tobin, T. (2011). Race is not neutral: a national investigation of African American and Latino disproportionality in school discipline. School Psych. Rev. 40, 85-107.
Skiba, R. J., Michael, R. S., Nardo, A. C., and Peterson, R. (2000). The color of discipline: sources of racial and gender disproportionality in school punishment. Urban Rev. 34, 317-342. doi: 10.1023/A:1021320817372

Smith, M. L. (2015). A generation at risk: the ties between zero tolerance policies and the school-to-prison pipeline. McNair Scholars Res. J. 8, 125-141.

Snodgrass Rangel, V. (2018). A review of the literature on principal turnover. Rev. Educ. Res. 88, 87-124. doi: 10.3102/0034654317743197

Song, S. Y., and Swearer, S. M. (2016). The cart before the horse: the challenge and promise of restorative justice consultation in schools. J. Educ. Psychol. Consultation 26, 313-324. doi: 10.1080/10474412.2016.1246972

Spreitzer, G. (2007). Giving peace a chance: organizational leadership, empowerment, and peace. J. Organ. Behav. 28, 1077-1095. doi: 10.1002/job.487

Sugai, G., and Horner, R. R. (2006). A promising approach for expanding and sustaining school- wide positive behavior support. School Psychol. Rev. 35, 245-259.

Terjesen, M. D., Jacofsky, M., Froh, J., and DiGiuseppe, R. (2004). Integrating positive psychology into schools: implications for practice. Psychol. Sch. 41, 163-172. doi: $10.1002 /$ pits. 10148

Teske, S. C. (2011). A study of zero tolerance policies in schools: a multi-integrated systems approach to improve outcomes for adolescents. J. Child Adolesc. Psychiatr. Nursing 24, 88-97. doi: 10.1111/j.1744-6171.2011.00273.x

Thapa, A., Cohen, J., Guffey, S., and Alessandro, A. H.-D. (2013). A review of school climate research. Rev. Educ. Res. 83, 357-385. doi: 10.3102/0034654313483907

Turri, M. G., Mercer, S. H., McIntosh, K., Nese, R. N. T., Strickland-Cohen, K., and Hoselton, R. (2016). Examining barriers to sustained implementation of school-wide prevention practices. Assessment for Effective Interv. 42, 6-17. doi: $10.1177 / 1534508416634624$

Twemlow, S. W., Fonagy, P., and Sacco, F. C. (2005). A developmental approach to mentalizing communities: the peaceful schools experiment. Bull. Menninger Clinic 69, 265-281. doi: 10.1521/bumc.2005.69.4.265

Umbreit, M. S. (1999). "Avoiding the marginalization and "McDonaldization" of victim offender mediation: a case study in moving toward the mainstream," in Restorative Juvenile Justice, eds G. Bazemore, and L. Walgrave (Monsey, NY: Criminal Justice Press), 213-234.

Vélez, W., and Saenz, R. (2001). Toward a comprehensive model of the school leaving process among Latinos. School Psychol. Q. 16, 445-467. doi: 10.1521/scpq.16.4.445.19897

Vincent, C. G., Randall, C., Cartledge, G., Tobin, T. J., and Swain-Bradway, J. (2011). Toward a conceptual integration of cultural responsiveness and schoolwide positive behavior support. J. Positive Behav. Interv. 13, 219-229. doi: 10.1177/1098300711399765

Vincent, C. G., and Tobin, T. J. (2011). The relationship between implementation of school-wide positive behavior support (SWPBS) and disciplinary exclusion of students from various ethnic backgrounds with and without disabilities. J. Emot. Behav. Disord. 19, 217-232. doi: 10.1177/1063426610377329

Voelkel, R. H. J., and Chrispeels, J. H. (2017). Within-school differences in professional learning community effectiveness. J. School Leadersh. 27, 424-453.

Wachtel, T. (2013). Defining Restorative. International Institute for Restorative Practices, 1-2. Available online at: https://www.iirp.edu/pdf/DefiningRestorative.pdf

Watkins, N. D., and Aber, M. S. (2009). Exploring the relationships among race, class, gender, and middle school students' perceptions of school racial climate. Equity Excellence Educ. 42, 395-411. doi: 10.1080/10665680903260218

Weissberg, R. P., and O’Brien, M. U. (2004). What works in school-based social and emotional learning programs for positive youth development. Ann. Am. Acad. Pol. Soc. Sci. 591, 86-97. doi: 10.1177/0002716203260093

Weitekamp, E. (1999). “The history of restorative justice," in Restorative Juvenile Justice: Repairing the Harm of Youth Crime, eds G. Bazemore and L. Walgrave (Monsey, NY: Criminal Justice Press), 75-102.

Western, S. (2014). Leadership: A Critical Text. San Francisco, CA: Sage Publications.

What Works Clearinghouse (2018). Department of Institute of Education Sciences, National Center for Education Evaluation and Regional Assistance. What Works Clearinghouse. Available online at: https://ies.ed.gov/ncee/wwc/

Wheatley, M. (2006). Leadership and the New Science: Discovering Order in a Chaotic World. San Francisco, CA: Berrett-Koehler. 
Wilber, K. (2000). A Theory of Everything: An Integral Vision for Business, Politics, Science, and Spirituality. San Francisco, CA: Shambhala Publishing.

Williams, A. (2011). A call for change: narrowing the achievement gap between white and minority students. Clearing House 84, 65-71. doi: $10.1080 / 00098655.2010 .511308$

Williams, J. M. G., and Kabat-Zinn, J. (2011). Mindfulness: Diverse perspectives on its meaning, origins, and multiple applications at the intersection of science and dharma. Contemp. Buddhism 12, 1-18. doi: 10.1080/14639947.2011. 564811

Williams, T. (2013). Unleashing sustainable leadership in schools: the paradox of distributed leadership. Educ. Res. J. 28, 33-50.

You, S., O'Malley, M. D., and Furlong, M. J. (2014). Preliminary development of the brief-California school climate survey: dimensionality and measurement invariance across teachers and administrators. School Effectiveness School Impr. 25, 153-173. doi: 10.1080/09243453.2013.784199
Zullig, K. J., Koopman, T. M., Patton, J. M., and Ubbes, V. A. (2010). School climate: historical review, instrument development, and school assessment. J. Psychoeduc. Assess. 28, 139-152. doi: 10.1177/0734282909344205

Conflict of Interest Statement: The authors declare that the research was conducted in the absence of any commercial or financial relationships that could be construed as a potential conflict of interest.

Copyright (c) 2018 McIntyre Miller and Abdou. This is an open-access article distributed under the terms of the Creative Commons Attribution License (CC BY). The use, distribution or reproduction in other forums is permitted, provided the original author(s) and the copyright owner(s) are credited and that the original publication in this journal is cited, in accordance with accepted academic practice. No use, distribution or reproduction is permitted which does not comply with these terms. 